Article

\title{
Performance Analysis of the Supercritical Carbon Dioxide Re-compression Brayton Cycle
}

\author{
Mohammad Saad Salim, Muhammad Saeed ${ }^{\dagger}$ and Man-Hoe Kim * $\mathbb{C}$ \\ School of Mechanical Engineering \& IEDT, Kyungpook National University, Daegu 41566, Korea; \\ msaadsalim@hotmail.com (M.S.S.); saeed.aarib@gmail.com (M.S.) \\ * Correspondence: kimmh@asme.org; Tel.: +82-53-950-5576 \\ + Present Address: Mechanical Engineering Department, Khalifa University of Science and Technology, \\ SAN Campus, P.O. Box 2533, Abu Dhabi, UAE.
}

Received: 30 December 2019; Accepted: 5 February 2020; Published: 7 February 2020

\begin{abstract}
This paper presents performance analysis results on supercritical carbon dioxide $\left(\mathrm{sCO}_{2}\right)$ re-compression Brayton cycle. Monthly exergy destruction analysis was conducted to find the effects of different ambient and water temperatures on the performance of the system. The results reveal that the gas cooler is the major source of exergy destruction in the system. The total exergy destruction has the lowest value of $390.1 \mathrm{~kW}$ when the compressor inlet temperature is near the critical point (at $35^{\circ} \mathrm{C}$ ) and the compressor outlet pressure is comparatively low (24 MPa). The optimum mass fraction $(x)$ and efficiency of the cycle increase with turbine inlet temperature. The highest efficiency of $49 \%$ is obtained at the mass fraction of $x=0.74$ and turbine inlet temperature of $700{ }^{\circ} \mathrm{C}$. For predicting the cost of the system, the total heat transfer area coefficient $\left(U A_{\text {Total }}\right)$ and size parameter $(S P)$ are used. The $U A_{\text {Total }}$ value has the maximum for the split mass fraction of 0.74 corresponding to the maximum value of thermal efficiency. The $S P$ value for the turbine is $0.212 \mathrm{dm}$ at the turbine inlet temperature of $700{ }^{\circ} \mathrm{C}$ and it increases with increasing turbine inlet temperature. However the $S P$ values of the main compressor and re-compressor increase with increasing compressor inlet temperature.
\end{abstract}

Keywords: re-compression Brayton cycle; carbon dioxide; supercritical; thermodynamic; exergy; cycle simulation; design point analysis

\section{Introduction}

The main cause of pollution is the combustion of fossil fuels to create energy for heavy industrialization and urbanization. Fossil fuel reserves are diminishing due to this process; thus, a big demand for power generation from green energy sources at high efficiency has been created. Global warming is another big concern, as has been pointed out by the United Nations Framework Convention on Climate Change (UNFCC). The proposal from the conference was to undertake efforts so that the rise in global average temperature increase could be limited to well below $2{ }^{\circ} \mathrm{C}$ above preindustrial levels. Due to the use of fossil fuels and harmful working fluids, significantly harmful effects on the environment are causing problems such as global warming and acid rain. The effects of pollution tend to bring unpredictable changes in the global climate, as has been asserted by the Intergovernmental Panel on Climate Change (IPCC), and rising sea levels are making large parts of the Earth uninhabitable [1]. Thus, green sources of energy are the need of the hour to solve these issues, which has led to research being conducted on different forms of green energy, such as biogas [2,3], geothermal energy [4,5], energy from human excreta [6] and solar energy [7]. In order to cope with the aforementioned global climate challenges, carbon dioxide $\left(\mathrm{CO}_{2}\right)$-based power systems present an environmentally friendly option and are capable of providing power at high efficiency. 
The Rankine cycle and the air-standard Brayton cycle are well-known thermodynamic cycles. The benefit of the Rankine cycle is that high efficiency can be achieved because the pump consumes a very small amount of work, since compression is carried out when the working fluid is in the liquid state [8]. The advantage of the Brayton cycle is that the turbine inlet temperature is high; thus, it can achieve high efficiency, but the disadvantage is that the work consumed by the compressor is very large. Due to this, the air-standard Brayton cycle's efficiency is not significantly higher than that of the steam-based Rankine cycle. The primary advantage of the supercritical $\mathrm{CO}_{2}\left(\mathrm{sCO}_{2}\right)$ Brayton cycle is that the positive points of the steam-based Rankine cycle and air-standard Brayton cycle are both combined. The turbine inlet temperature in the $s \mathrm{CO}_{2}$ Brayton cycle is high. Moreover, since the compressor operates near the $\mathrm{CO}_{2}$ critical point at very high pressure at which the density is significantly high and the compressibility factor is small, the work that is consumed by the compressor is significantly low. The $s \mathrm{SO}_{2}$ Brayton cycle operates above the critical point, so the need for condensing the system is removed and the system has a simple layout. Since the $\mathrm{sCO}_{2}$ re-compression Brayton cycle has very high operating pressures compared to the steam-based Rankine cycle, the size of the $s \mathrm{CO}_{2}$-based power system's components is considerably smaller [9].

Currently, extensive research is being conducted on $\mathrm{sCO}_{2}$-based power systems, and the $\mathrm{sCO}_{2}$ Brayton cycle can be found in a variety of arrangements in the literature, such as in reheated and intercooled re-compression layouts [10]. Crespi et al. [11] reviewed the different single and combined layouts of $\mathrm{sCO}_{2}$ Brayton cycle power systems with efficiencies of $40 \%-50 \%$ and $50 \%-60 \%$, respectively, while Saeed and Kim [8] analyzed a re-compression $\mathrm{sCO}_{2}$ Brayton cycle power system with an integrated turbine design and optimization algorithm. In their study, they proposed that the cycle performs best when the inlet temperature of the compressor is set near the $\mathrm{CO}_{2}$ critical temperature (i.e., $32-37^{\circ} \mathrm{C}$ ) and the compressor inlet pressure is set slightly above the $\mathrm{CO}_{2}$ critical pressure (i.e., 7.8-8.1 MPa) along with a moderate pressure ratio (i.e., 2.9-3.1). Saeed et al. [12] carried out a design optimization and performance analysis of the $\mathrm{SCO}_{2}$ re-compression Brayton cycle. They developed detailed mathematical models of the cycle components and simulation codes for the turbine, compressor and heat exchanger. These codes were used to analyze the performance of the cycle under the design conditions as well as off-design conditions.

To analyze the performances of thermal power systems, researchers have used different performance parameters, including thermal efficiency $\left(\eta_{t h}\right)$ and exergy efficiency $\left(\eta_{\text {ex }}\right)$. Moreover, to indicate the cost and size of the thermodynamic system, parameters such as the total heat transfer area coefficient $\left(U A_{\text {Total }}\right)$ and size parameter $\left(S P_{\text {Total }}\right)$ have also been used to indicate the heat exchanger and turbomachinery sizes, respectively [13-15]. Patel et al. [16] studied the optimization of a waste-heat-based organic Rankine cycle (ORC)-powered cascaded vapor compression-absorption refrigeration system. They used the log mean temperature difference (LMTD) to determine the $U A$ value of each heat exchanger in the system. The purpose was to minimize the $U A$ value in order to minimize the area required for heat exchange, and thus minimize the cost of the heat exchangers in the system.

This paper presents the various benefits of $s \mathrm{CO}_{2}$ power systems. A detailed investigation has been conducted for the performance of the system with regard to key performance parameters such as $\eta_{t h}, \eta_{e x}, U A$ and size parameter $(S P)$ of the turbomachinery. The system analysis also has been performed on the basis of the changing ambient temperature $\left(T_{0}\right)$ and water temperature $\left(T_{w, i_{n}}\right)$ values to signify how the system's exergetic performance changed on a monthly basis. To the author's best knowledge, monthly/seasonal analysis using for $\mathrm{sCO}_{2}$-based power systems are not available in the literature. Moreover, the performance of the system at different turbine inlet temperatures $\left(T_{7}\right)$, compressor inlet temperatures $\left(T_{1}\right)$ and compressor outlet pressures $\left(P_{2}\right)$ is also presented to signify the effect of each variable on various performance parameters of the system, and to indicate which values are best for use as the cycle's design points. 


\section{Methodology}

\subsection{Cycle Processes}

Figure 1 shows a cycle layout and temperature-entropy (T-s) diagram of the system considered in the study. As shown in Figure 1a, the system consists of a turbine, a primary heat exchanger, high and low-temperature recuperators, the main compressor, a re-compression compressor and a gas cooler. In comparison with the recuperated cycle, the re-compression Brayton cycle includes an added intermediate compressor, an additional recuperator and split/mixing flow values. A fraction of mass is taken from the mainstream and fed to the re-compression compressor bypassing the low-temperature recuperator (LTR). This fraction of flow enters the mainstream again increases its temperature before entering into the high-temperature recuperator (HTR). This arrangement in turns increases the thermal efficiency of the cycle ( $42 \%$ to $50 \%$ for cycles operating with the lowest and highest temperatures, 37 ${ }^{\circ} \mathrm{C}$ and $700{ }^{\circ} \mathrm{C}$ respectively [10]) by reducing heat rejection in the pre-cooler.

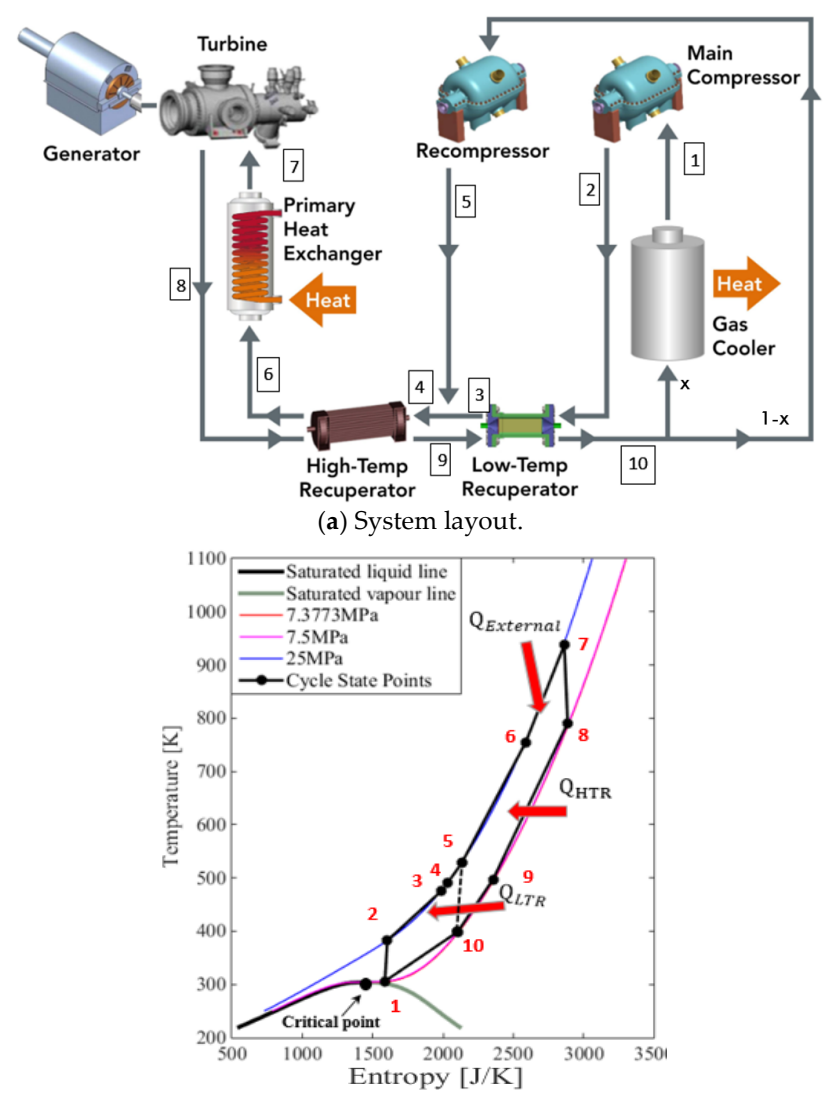

(b) Temperature-entropy (T-s) diagram.

Figure 1. Schematic of re-compression $\mathrm{sCO}_{2}$ Brayton cycle.

The stream exiting the re-compressor in State 5 and the stream exiting the recuperator in State 3 are combined in State 4. This stream then passes the HTR where its temperature further increases to State 6. After this, the heat addition process takes place at the main heat exchanger and the stream reaches $T_{7}$ in State 7 . In the turbine, the expansion process takes place until State 8 . From State 8 to State 9, the HTR recuperates heat, and then, from State 9 to State 10, the LTR recuperates heat. After this, cooling takes place in the gas-cooler in State Point 1 . The gas cooling process from State 10 to State 1 is used to transfer heat to the coolant (water) which is input to the gas cooler at the monthly temperature value (see Figure 2) and has to be heated to $40{ }^{\circ} \mathrm{C}$ for domestic uses, such as floor heating. 


\subsection{Design Parameters}

The cycle simulations were developed using MATLAB [17], and the thermodynamic properties of $\mathrm{CO}_{2}$ at each state point in the cycle were calculated NIST's REFPROP [18]. The design parameters and governing equations for defining the operation of the cycle are listed in Table 1.

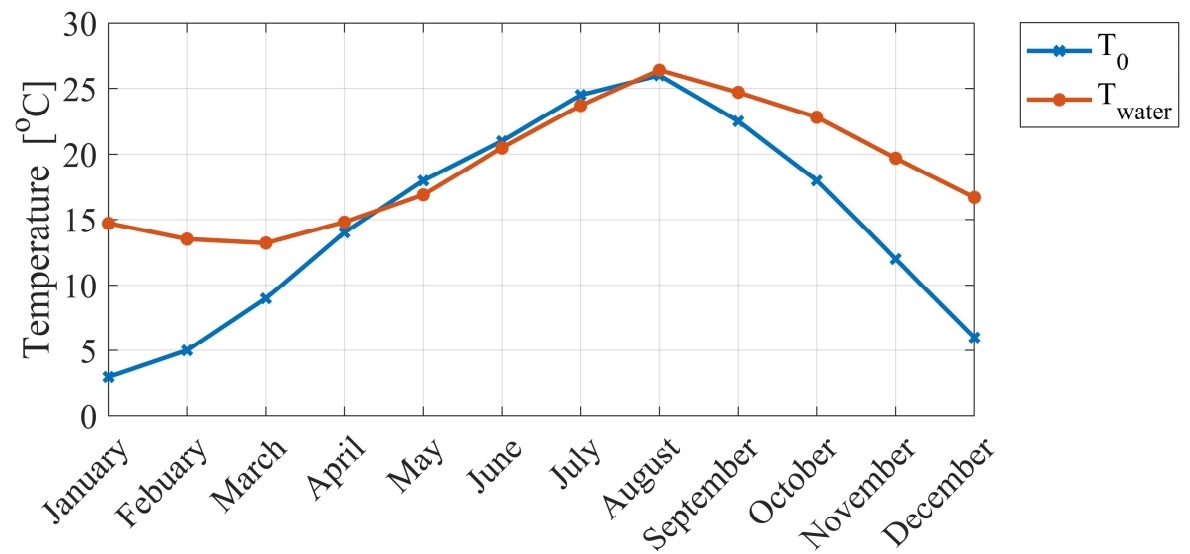

Figure 2. Ambient and water temperature data for the city of Busan [19].

Table 1. Design parameters used in $\mathrm{sCO}_{2}$ cycle simulations.

\begin{tabular}{ccc}
\hline Parameter & Symbol & Value \\
\hline Main compressor inlet temperature, ${ }^{\circ} \mathrm{C}$ & $m_{\mathrm{CO}_{2}}$ & 10 \\
Main compressor inlet pressure, $\mathrm{MPa}$ & $T_{1}$ & 35 \\
Main compressor outlet pressure, $\mathrm{MPa}$ & $P_{1}$ & 7.8 \\
Main compressor isentropic efficiency & $P_{2}$ & 24 \\
Re-compressor isentropic efficiency & $\eta_{M C}$ & 0.85 \\
Turbine isentropic efficiency & $\eta_{R C}$ & 0.85 \\
Effectiveness of the HTR & $\eta_{T}$ & 0.93 \\
Effectiveness of the LTR & $\varepsilon_{H T R}$ & 0.90 \\
Ambient pressure, MPa & $\varepsilon_{L T R}$ & 0.90 \\
Ambient temperature (other than seasonal exergy analysis), ${ }^{\circ} \mathrm{C}$ & $T_{0}$ & 24.5 \\
Water inlet temperature in the gas cooler (other than seasonal exergy analysis), ${ }^{\circ} \mathrm{C}$ & $P_{0}$ & 0.1 \\
Water outlet temperature in the gas cooler, ${ }^{\circ} \mathrm{C}$ & $T_{w, \text { in }}$ & 23.7 \\
\hline
\end{tabular}

For the monthly exergy analysis presented in this study, ambient temperature $\left(T_{0}\right)$ and water (coolant) inlet temperatures $\left(T_{w, \text { in }}\right)$ in the gas cooler were used from the data for the city of Busan [19] as shown in Figure 2.

\subsection{Energy and Exergy Analysis}

To simplify the analysis, the following assumptions are made:

1. Pressure drops in the heat exchangers and pipes are neglected.

2. Steady-state operation is assumed for all the devices in the system.

3. Heat loss from the components is negligible.

The following set of governing equations represent the energy analysis for the $\mathrm{sCO}_{2}$ cycle:

$$
\begin{gathered}
W_{T}=m_{\mathrm{CO}_{2}}\left(h_{7}-h_{8}\right), \\
W_{M C}=m_{\mathrm{CO}_{2}} x\left(h_{2}-h_{1}\right), \\
W_{R C}=m_{\mathrm{CO}_{2}}(1-x)\left(h_{5}-h_{10}\right),
\end{gathered}
$$




$$
\begin{gathered}
Q_{i n}=m_{\mathrm{CO}_{2}}\left(h_{7}-h_{6}\right), \\
Q_{G C}=m_{\mathrm{CO}_{2}} x\left(h_{10}-h_{1}\right), \\
W_{\text {net }}=W_{T}-W_{M C}-W_{R C}, \\
\eta_{\text {th }}=\frac{W_{\text {net }}}{Q_{\text {in }}} .
\end{gathered}
$$

Thermal efficiency $\left(\eta_{t h}\right)$ is a parameter that takes into account how much of the energy input from the heat source is converted into the net shaft work by the turbine, but it does not reflect the irreversibilities that are involved in the $\mathrm{sCO}_{2}$ re-compression Brayton cycle. The exergy analysis of the system is significantly useful, since energy is conserved but exergy is destroyed by the irreversibility [20]. The second law (exergy) efficiency of the system is an indicator of the maximum theoretical work that can be generated as the system is brought to equilibrium with the environment.

The specific exergy of flow at any state in the system is given by

$$
e=h-h_{0}-T_{0}\left(s-s_{0}\right) .
$$

By applying exergy balance over each component, the exergy destruction in the different components of the system can be defined as follows.

Primary heat exchanger:

$$
I_{\mathrm{HX}}=m_{\mathrm{CO}_{2}}\left(e_{6}-e_{7}\right)+m_{s}\left(e_{s i}-e_{s o}\right),
$$

where $m_{s}$ is the mass flow rate of the heat transfer fluid.

Main compressor:

$$
I_{M C}=m_{C_{2}} x\left(e_{1}-e_{2}\right)+W_{M C} .
$$

Re-compressor:

$$
I_{R C}=m_{C_{2}}(1-x)\left(e_{10}-e_{5}\right)+W_{R C} .
$$

Gas cooler:

$$
I_{G C}=m_{C O_{2}} x\left(e_{10}-e_{1}\right)+m_{w}\left(e_{w i n}-e_{w o u t}\right) .
$$

Turbine:

$$
I_{T}=m_{\mathrm{CO}_{2}}\left(e_{7}-e_{8}\right)-W_{T} .
$$

High-temperature recuperator:

$$
I_{H T R}=m_{\mathrm{CO}_{2}}\left(e_{8}-e_{9}+e_{4}-e_{6}\right) .
$$

\section{Low-temperature recuperator:}

$$
I_{L T R}=m_{\mathrm{CO}_{2}}\left[e_{9}-e_{10}+x\left(e_{2}-e_{3}\right)\right] .
$$

The total exergy destruction in the system is given by

$$
I_{\text {Total }}=I_{H X}+I_{M C}+I_{R C}+I_{G C}+I_{T}+I_{H T R}+I_{L T R} .
$$

The heat rejection from the system in the gas cooling process, which can be utilized for district heating purposes, is determined from the following equation:

$$
Q_{\text {out }}=m_{w}\left(h_{\text {wout }}-h_{\text {win }}\right) .
$$


By balancing the exergy throughout the whole system, the exergy input to the system is

$$
E_{\text {in }}=W_{\text {net }}+I_{\text {Total }}+\left(\frac{T_{0}}{T_{w a v g}}-1\right) Q_{o u t} .
$$

The exergy efficiency of the system is given by

$$
\eta_{\text {ex }}=\frac{W_{\text {net }}}{E_{\text {in }}} .
$$

The total irreversibility ratio (IR) of the system can be written as

$$
I R=\frac{I_{\text {total }}}{E_{\text {in }}} .
$$

\subsection{Total Heat Transfer Area Coefficient and Total Size Parameter Value $\left(S P_{\text {Total }}\right)$}

$U A_{\text {Total }}$ and $S P_{\text {Total }}$ are useful parameters for estimating the cost of the system. $U A_{\text {Total }}$ indicates the total area required for the heat exchangers in the $s \mathrm{CO}_{2}$ re-compression Brayton cycle, and thus the cost associated with the investment and maintenance of the heat exchangers. The hypothesis is that differences between the heat transfer coefficients in the $\mathrm{sCO}_{2}$ cycle heat exchangers are not significant. The total heat transfer area in the heat exchangers increases as a result of increasing $U A_{\text {Total }}$, thereby increasing the investment and maintenance costs of the heat exchangers, and thus the system [21]. A smaller value of $U A_{\text {Total }}$ is desirable for a cost-effective design.

For a heat exchanger in general, we have

$$
\begin{gathered}
U A=\frac{Q}{\Delta T_{M}}, \\
\Delta T_{M}=\frac{\Delta T_{\max }-\Delta T_{\min }}{\ln \left(\frac{\Delta T_{\max }}{\Delta T_{\min }}\right)},
\end{gathered}
$$

where $\Delta T_{M}$ is logarithmic mean temperature difference and $\Delta T_{\max }$ and $\Delta T_{\min }$ are the maximum and minimum temperature differences, respectively, at the two ends of the heat exchanger. However, in the case of supercritical carbon dioxide Brayton cycle $\left(\mathrm{sCO}_{2}-\mathrm{BC}\right)$, properties of the working fluid change swiftly, and the definition of the $\Delta T_{M}$ is not applicable in this case. In order to cope with the situation, the length of the heat exchanger was divided into $\mathrm{N}$ number of segments. The length of each segment was kept small enough that the variation within a particular small segment can be ignored, as shown in Figure 3. The value of the number of segments $(\mathrm{N})$ depends upon the operation region of the heat exchanger. For the pre-cooler and LTR, the numbers of segments will be large, as these two heat exchangers operate close to the critical point, and properties of $s \mathrm{CO}_{2}$ change at high rates. For HTR, in contract with LTR and pre-cooler, but operating away from the critical point where variation in the properties is small, a lesser number of segments would be required. Further details on the model can be found in the previous studies $[8,12,22,23]$.

Based on the discretized model definition of the logarithmic mean temperature difference $\left(\Delta T_{M}\right)^{i}$, the $i^{\text {th }}$ segment is given by the Equation (23)

$$
\begin{gathered}
\left(\theta_{2}\right)^{\mathrm{i}}=\left(\mathrm{T}^{\mathrm{h}}\right)^{\mathrm{i}}-\left(\mathrm{T}^{\mathrm{c}}\right)^{\mathrm{i}} ; \\
\left(\theta_{1}\right)^{\mathrm{i}}=\left(\mathrm{T}^{\mathrm{h}}\right)^{\mathrm{i}+1}-\left(\mathrm{T}^{\mathrm{c}}\right)^{\mathrm{i}+1} ; \\
\left(\Delta \mathrm{T}_{\mathrm{M}}\right)^{\mathrm{i}}=\frac{\max \left(\left(\theta_{1}\right)^{\mathrm{i}},\left(\theta_{2}\right)^{\mathrm{i}}\right)-\min \left(\left(\theta_{1}\right)^{\mathrm{i}},\left(\theta_{2}\right)^{\mathrm{i}}\right)}{\log \left(\frac{\max \left(\left(\theta_{1}\right)^{\mathrm{i}},\left(\theta_{2}\right)^{\mathrm{i}}\right)}{\min \left(\left(\theta_{1}\right)^{\mathrm{i}},\left(\theta_{2}\right)^{\mathrm{i}}\right)}\right)}
\end{gathered}
$$


Thus, UA value through the $i^{\text {th }}$ segment could be computed as given by the following equation.

$$
(U A)^{i}=\frac{(d q) i}{\left(\Delta T_{M}\right)^{i}} .
$$

And UA value associated with the whole heat exchanger can be calculated using the following relation.

$$
U A=\sum_{i=1}^{N}(U A)^{i}
$$

Later, combining the $U A$ values for the $\mathrm{SCO}_{2}$ system, we obtain

$$
U A_{T o t a l}=U A_{H X}+U A_{H T R}+U A_{L T R}+U A_{G C} .
$$

$S P$ indicates the size of the turbomachinery in the system, and a high $S P_{\text {Total }}$ means comparatively large sizes of the turbine and compressors. Consequently, the investment and maintenance costs of the turbomachinery will increase, which, in turn, will increase the total cost of the system. Because of this, a small $S P_{\text {Total }}$ is desirable.

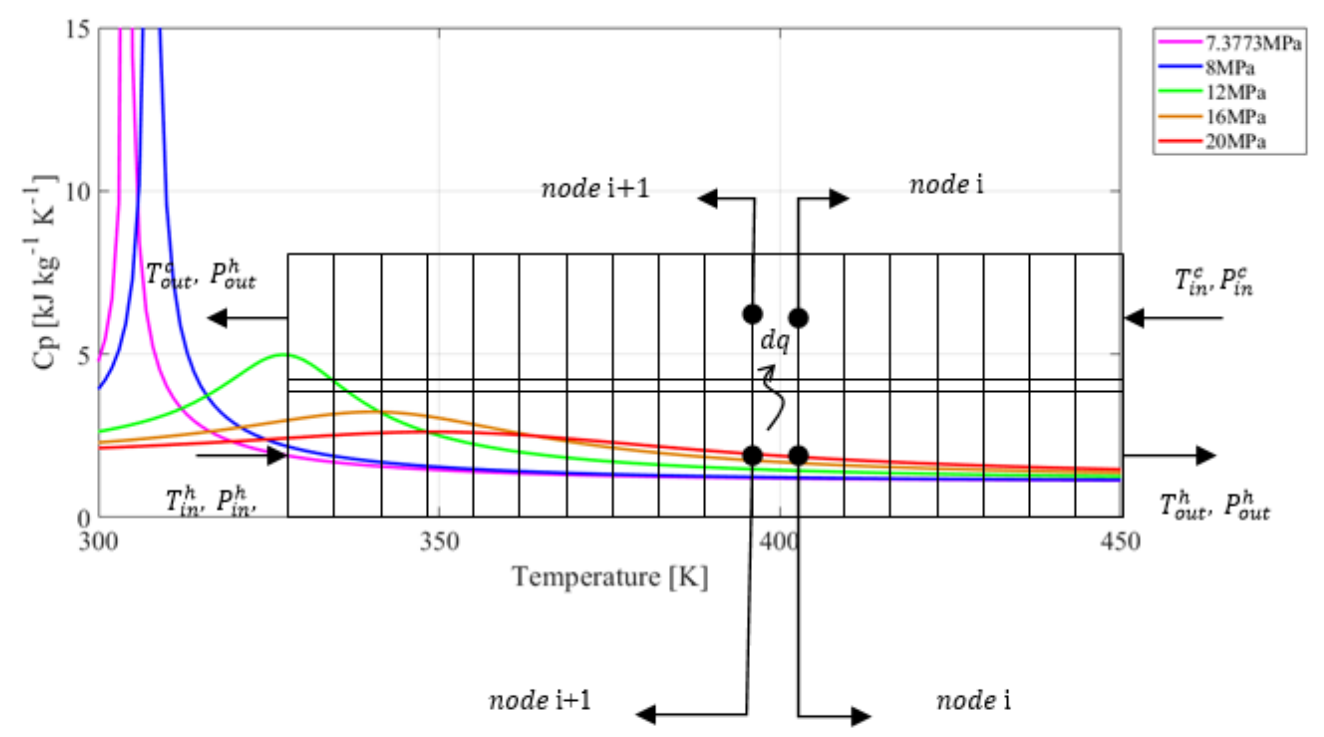

Figure 3. Discretized model of the heat exchanger to capture the effect of variation in the properties of $\mathrm{sCO}_{2}$.

Macchi and Perdichizzi [14] used the turbine SP to determine the expander size, which for the $s \mathrm{CO}_{2}$ re-compression Brayton cycle, is given by

$$
S P_{T}=\frac{\sqrt{V_{8 s}}}{\sqrt[4]{\Delta h_{s}}}=\frac{\sqrt{m_{\mathrm{CO}_{2} v_{8 s}}}}{\sqrt[4]{h_{7}-h_{8 s}}},
$$

where $V_{8 s}$ is the isentropic value of the volume flow rate of the working fluid at the turbine exit, and $\Delta h_{s}$ is the isentropic specific enthalpy drop.

The main compressor and re-compression compressor $S P$ values can be respectively defined as

$$
S P_{M C}=\frac{\sqrt{m_{\mathrm{CO}_{2}} x v_{1}}}{\sqrt[4]{h_{2 s}-h_{1}}}
$$




$$
S P_{R C}=\frac{\sqrt{m_{\mathrm{CO}_{2}}(1-x) v_{10}}}{\sqrt[4]{h_{5 s}-h_{10}}}
$$

For the system under study,

$$
S P_{\text {Total }}=S P_{T}+S P_{M C}+S P_{R C}
$$

Hence,

$$
(S P)_{\text {Total }}=\frac{\sqrt{m_{\mathrm{CO}_{2} v_{8 s}}}}{\sqrt[4]{h_{7}-h_{8 s}}}+\frac{\sqrt{m_{\mathrm{CO}_{2}} x v_{1}}}{\sqrt[4]{h_{2 s}-h_{1}}}+\frac{\sqrt{m_{\mathrm{CO}_{2}}(1-x) v_{10}}}{\sqrt[4]{h_{5 s}-h_{10}}} .
$$

\subsection{Properties of $\mathrm{SCO}_{2}$}

The selection of the working fluid has an important role in optimizing the performance of the system. Efficiency, cost and environmental aspects are key performance metrics that need to be considered before selecting a working fluid. Amongst the desired characteristics are an ozone depletion potential (ODP) of 0 and a low global warming potential (GWP) value. Table 2 lists the properties of $\mathrm{CO}_{2}$, which is the working fluid used for the system in the study. Moreover, $\mathrm{CO}_{2}$ is a non-toxic, cheap and easily available substance. A point of interest is that $\mathrm{CO}_{2}$ has a critical temperature that is very close to the ambient temperature; thus, it is relatively easy for it to be used in the supercritical state, and it can be matched to a number of power cycles. The properties of $\mathrm{CO}_{2}$ show large variations near their critical points, which is highly advantageous for the compression process. With a small increase in temperature, the energy of the fluid increases significantly during the compression process, thereby making it highly efficient [10].

Table 2. Typical properties of $\mathrm{CO}_{2}$.

\begin{tabular}{ccccc}
\hline $\begin{array}{c}\text { Molar Mass } \\
(\mathrm{g} / \mathrm{mol})\end{array}$ & $\begin{array}{c}\text { Critical Pressure } \\
\mathbf{( M P a})\end{array}$ & $\begin{array}{c}\text { Critical } \\
\text { Temperature }\left({ }^{\circ} \mathbf{C}\right)\end{array}$ & ODP & GWP \\
\hline 44.01 & 7.4 & 31.0 & 0 & 1 \\
\hline
\end{tabular}

\section{Results and Discussion}

\subsection{Thermal Efficiency $\left(\eta_{t h}\right)$}

Figure 4 shows thermal efficiency, $\eta_{t h}$ of the $s \mathrm{CO}_{2}$ system. As expected, the increment of $T_{7}$ increases the efficiency of the system, meaning that more power output can be derived for the same heat input. The optimal value for the split mass fraction $(x)$ is the one for which the thermal efficiency shows the maximum value for each $T_{7}$ case. Moreover, as $T_{7}$ increases, the optimal value of $x$ slightly shifts to the right. The best efficiency is at $x=0.74$ and $T_{7}=700{ }^{\circ} \mathrm{C}$.

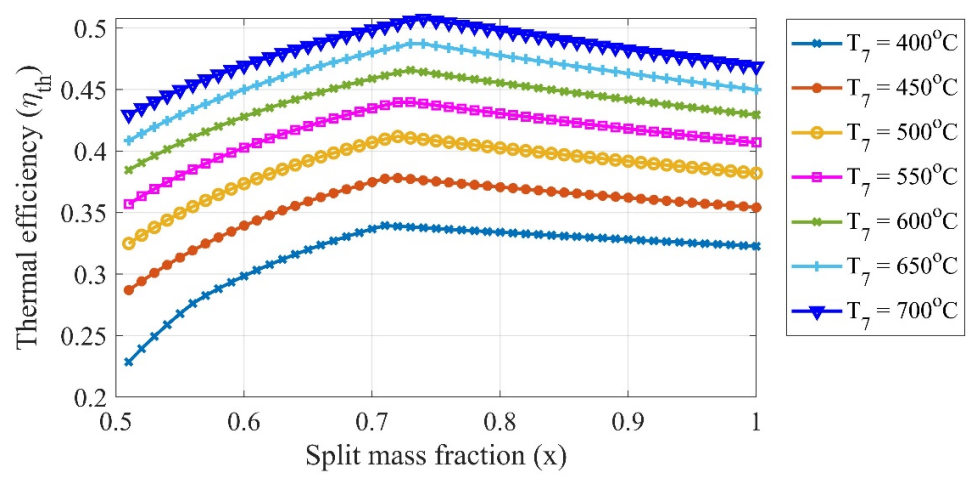

Figure 4. The thermal efficiency of the $s \mathrm{CO}_{2}$ cycle at different turbine inlet temperatures $\left(T_{7}\right)$. 


\subsection{Exergy Efficiency $\left(\eta_{e x}\right)$ and Irreversibility Ratio (IR)}

Figure 5 presents the $I R$ and the $\eta_{e x}$ values for the $T_{7}$ of $700{ }^{\circ} \mathrm{C}$. The optimal value for $x$ is the one for which $\eta_{e x}$ shows the maximum value. The $I R$ is the minimum, and at the same time, $\eta_{e x}$ is the maximum at $x=0.74$.

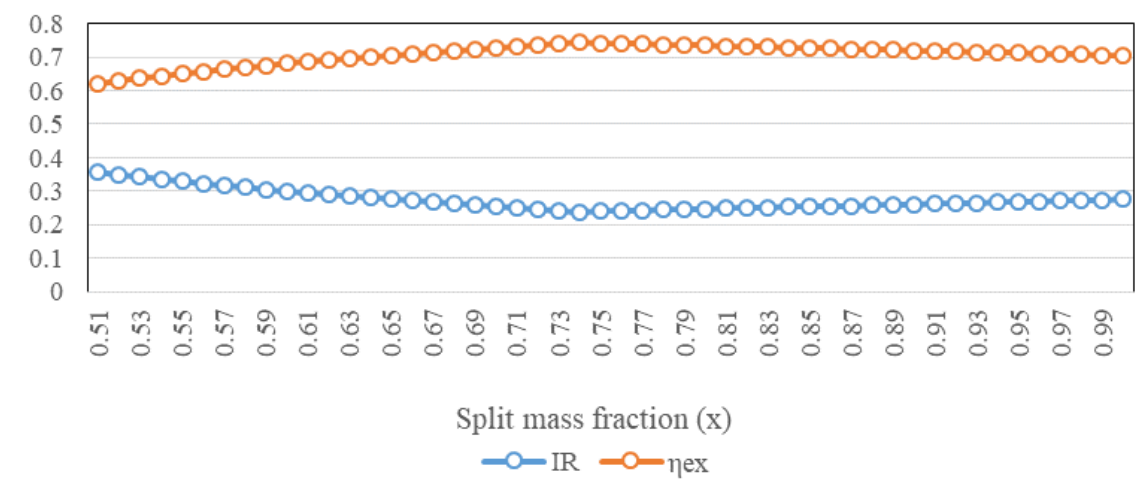

Figure 5. Exergy efficiency $\left(\eta_{e x}\right)$ and irreversibility ratio $(I R)$ of the $s \mathrm{CO}_{2}$ cycle at a turbine inlet temperature $\left(T_{7}\right)$ of $700{ }^{\circ} \mathrm{C}$.

\subsection{Exergy Destruction in Different Components}

The total exergy destruction of the $\mathrm{sCO}_{2}$ re-compression Brayton cycle increased with an increase in $T_{7}$, as shown in Figure 6. One of the reasons for this is the higher entropy generation at higher $T_{7}$ values causing comparatively higher exergy destruction in the turbine. Figure 7 presents the exergy destruction in different components of the $s \mathrm{CO}_{2}$ cycle at $T_{7}=700{ }^{\circ} \mathrm{C}$ and $x=0.74$. It can be observed that the gas cooler shows the maximum exergy destruction because a lot of exergy is destroyed when the $s \mathrm{CO}_{2}$ is cooled down from State 10 to State 1. Figure 8 shows that when the outlet pressure of the compressor is high, the exergy destruction is also comparatively high. Moreover, in the summer months, the exergy destruction was high because of high ambient and water temperatures. Figure 9 shows that as the compressor inlet temperature is kept to a lower value (near the critical point), the exergy destruction is minimized. The minimum exergy destruction of $390 \mathrm{~kW}$ was observed in January at a compressor inlet temperature of $35^{\circ} \mathrm{C}$ and a compressor outlet pressure of $24 \mathrm{MPa}$.

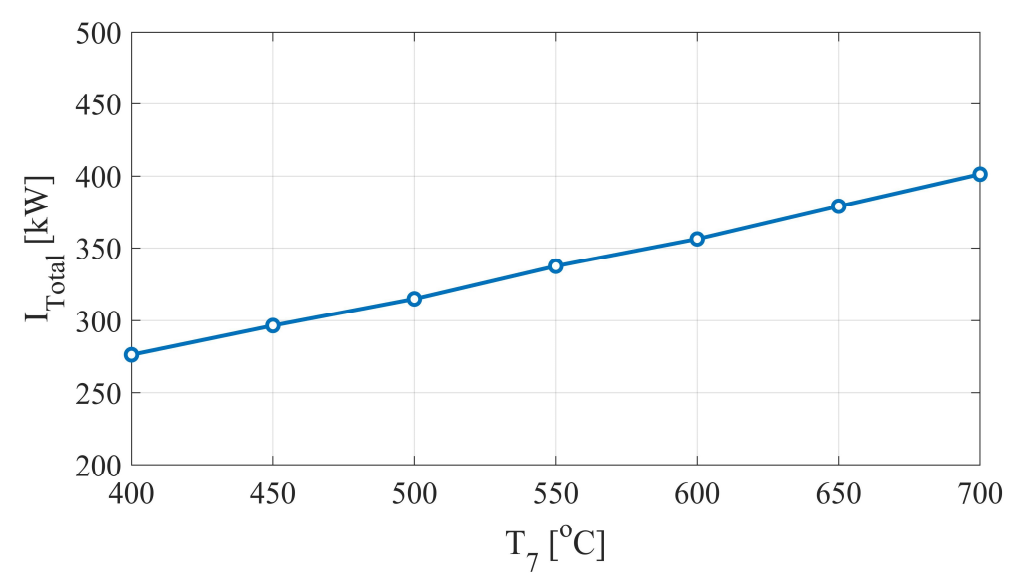

Figure 6. Total exergy destruction vs. turbine inlet temperature $\left(T_{7}\right)$. 


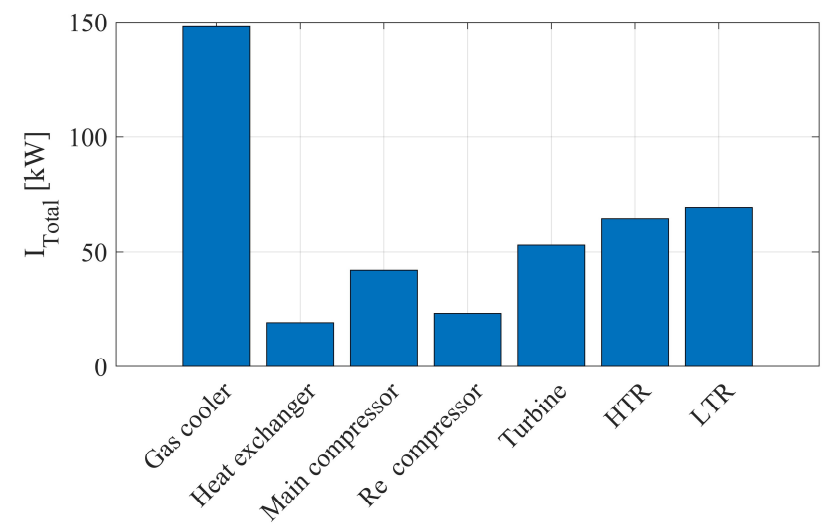

Figure 7. Exergy destruction in different components of the cycle at $T_{7}=700^{\circ} \mathrm{C}$.

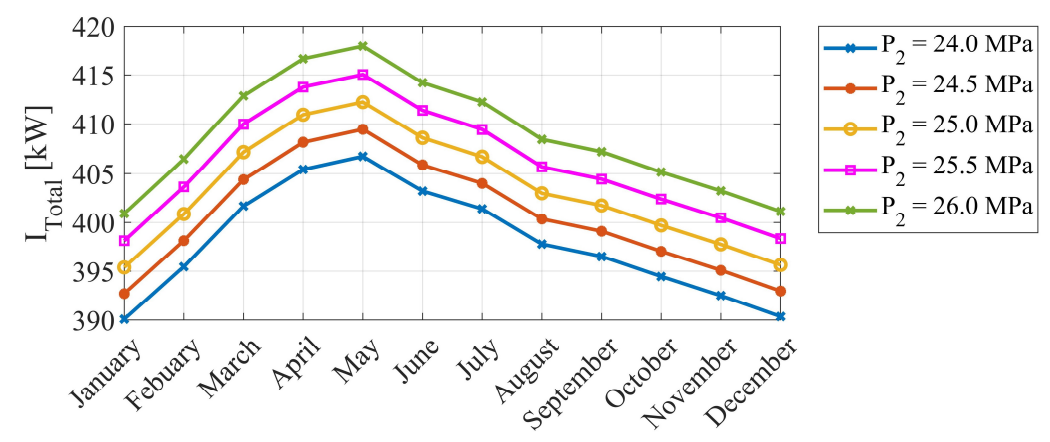

Figure 8. Total exergy destruction at different compressor outlet pressures $\left(\mathrm{P}_{2}\right)$.

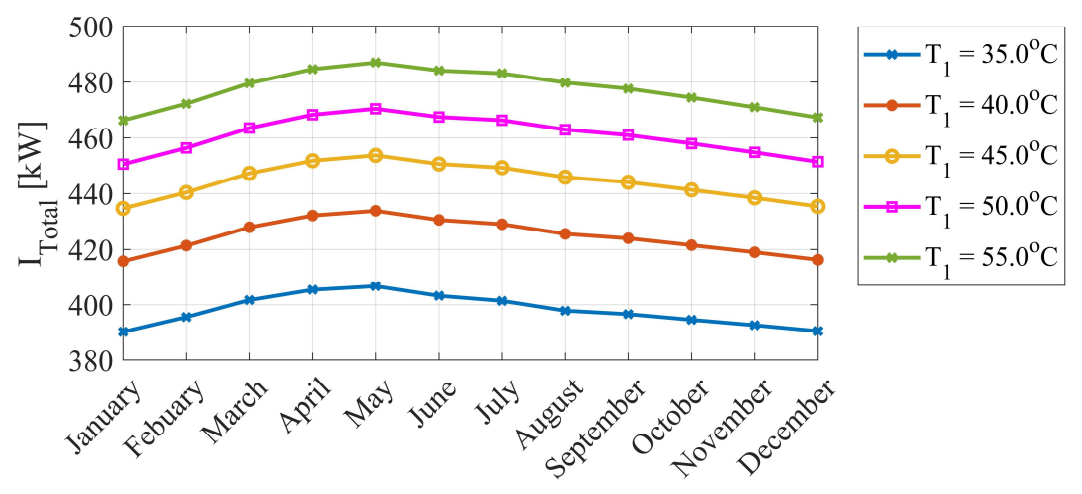

Figure 9. Total exergy destruction at different compressor inlet temperatures $\left(T_{1}\right)$.

\subsection{Heat Transfer Area Coefficient (UA) and Turbomachinery Size (SP) Values}

$U A$ and $S P$ values are the parameters for the estimation of the cost of the system. UA value indicates the area required for heat exchangers, and thus indicates their cost. As the UA value increases, the total heat transfer area in the heat exchangers also increases, thereby increasing the investment and maintenance costs of the heat exchangers, and thus the system [21]. SP values indicate the size of the turbomachinery in the system; thus, a lower value is desirable.

Figure 10 illustrates the relationship of $U A$ with the different heat exchangers in the $s \mathrm{CO}_{2}$ re-compression Brayton cycle with different $T_{7}$ values. It should be noted that the $U A$ value for the primary heat exchanger was the highest and increased at an increasing rate, whereas the $U A$ value for the HTR showed a linear increase with respect to $T_{7}$. The net result is that for a high $T_{7}$ value, a large heat exchange area is required when considering all of the heat exchangers in the system. The gas cooler showed the lowest $U A$ value and was not sensitive to $T_{7}$. 


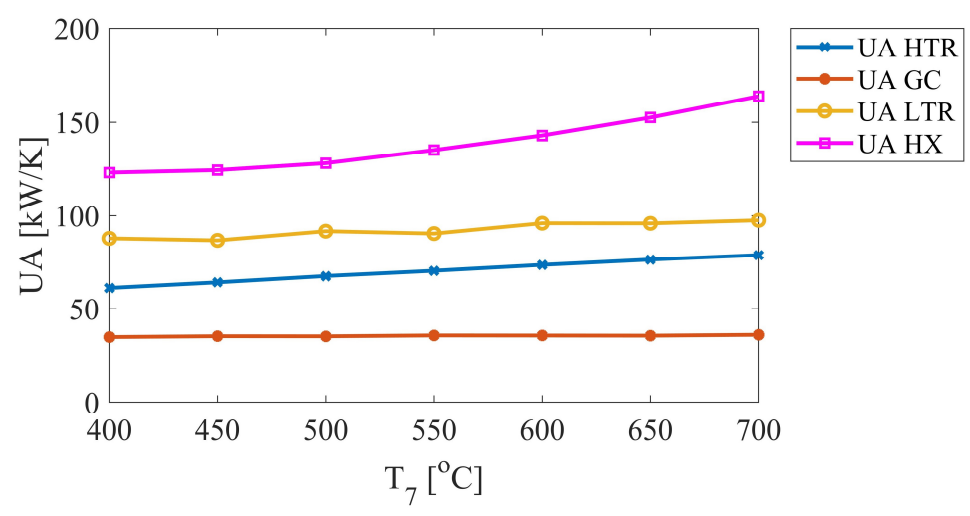

Figure 10. Heat transfer area coefficient $(U A)$ vs. turbine inlet temperature $\left(T_{7}\right)$.

Figure 11 shows the effect of $T_{1}$ on the heat exchanger sizes, as indicated by the $U A$ value for each heat exchanger. It should be noted that the $U A$ values of the primary heat exchanger, gas cooler and LTR all decrease with increasing $T_{1}$, whereas that of HTR shows only a slight increase. As shown in Figure 12, the net result was a decrease in the $U A_{\text {Total }}$ value with increasing $T_{1}$, which implies that the total area required for heat exchange decreases, and smaller heat exchanger sizes will be required for higher compressor inlet temperatures (which are much higher than the critical temperature value).

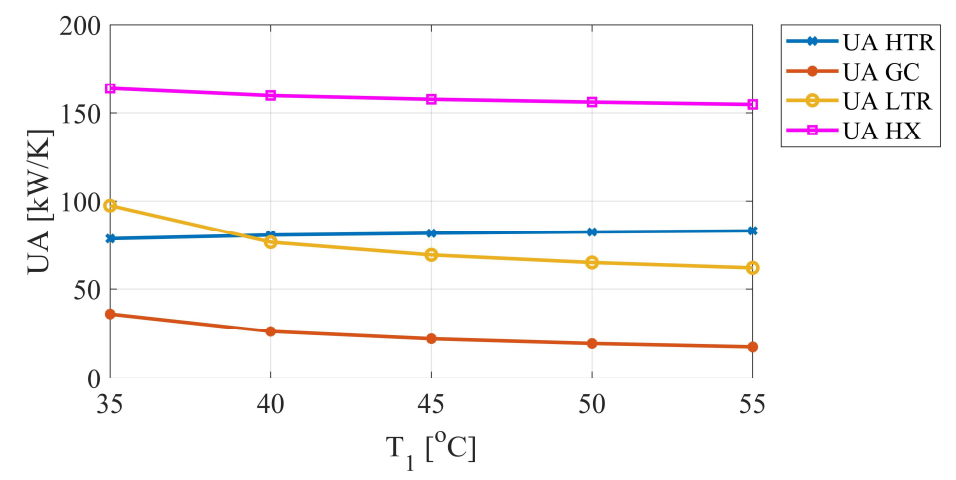

Figure 11. Heat transfer area coefficient $(U A)$ vs. compressor inlet temperature $\left(T_{1}\right)$.

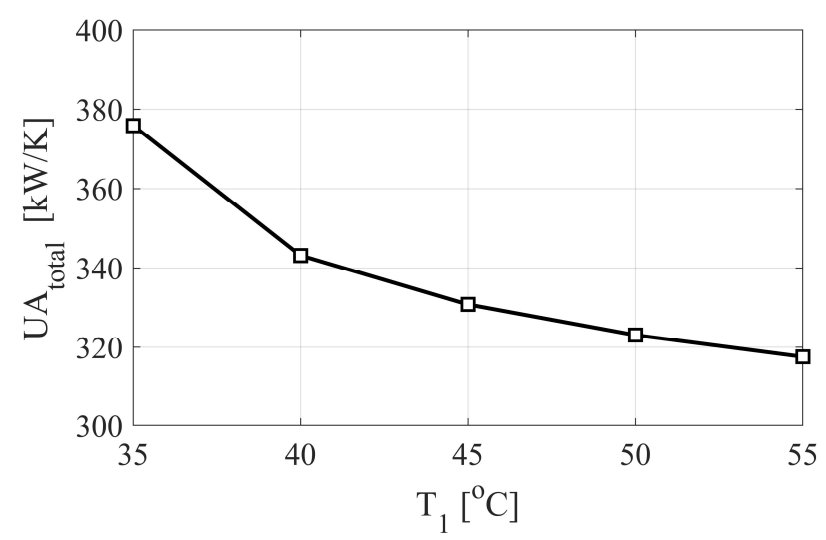

Figure 12. Total heat transfer area coefficient $\left(U A_{\text {Total }}\right)$ vs. compressor inlet temperature $\left(T_{1}\right)$.

Figure 13 shows the relationship between $U A_{\text {Total }}$ and $x$ in the $s \mathrm{CO}_{2}$ re-compression Brayton cycle. The plot shows a maximum $U A_{\text {Total }}$ value at $x=0.74$, which is the same point at which $\eta_{\text {th }}$ was maximum. This implies that the size, and thus, the cost of the heat exchangers in the system, will need to be high to achieve the maximum efficiency. 


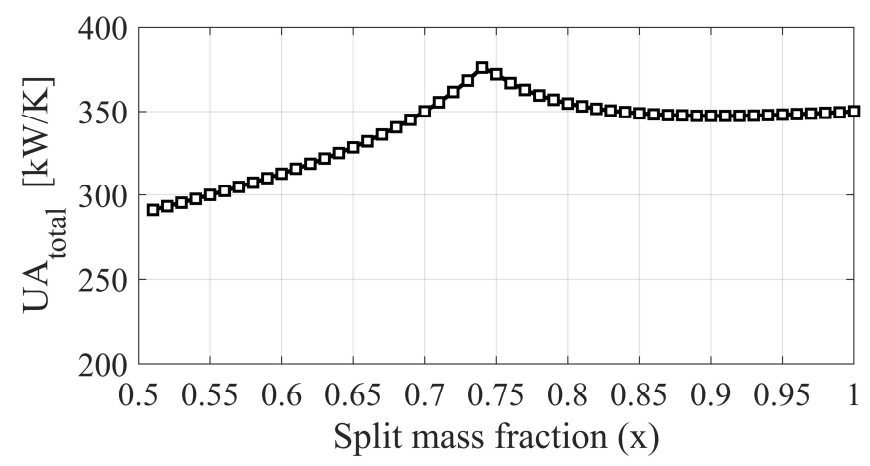

Figure 13. Total heat transfer area coefficient $\left(U A_{\text {Total }}\right)$ vs. split mass fraction $(x)$ at $T_{7}=700{ }^{\circ} \mathrm{C}$.

Figures 14 and 15 show the $S P$ values for the turbine, main compressor and re-compressor in the ${ }_{S} \mathrm{CO}_{2}$ cycle. The $S P$ of the turbine increases at higher $T_{7}$ values, implying that a large turbine should be used for high $T_{7}$ values. Moreover, the $S P$ values of the main compressor and re-compressor are much less sensitive to $T_{7}$, meaning that the same compressor size can be used when $T_{7}$ is either low or high. The main compressor has a higher $S P$ value than the re-compressor. Figure 15 shows the variation in $S P$ of the different turbomachinery components with $T_{1}$. The $S P$ of the turbine does not depend on $T_{1}$, as can be seen by the straight line. However, the $S P$ values of the main compressor and re-compressor increase with an increase in $T_{1}$. Moreover, the increase in the $S P$ value for the main compressor is more pronounced than that of the re-compressor. Hence, relatively large compressor sizes will be required at a high $T_{1}$.

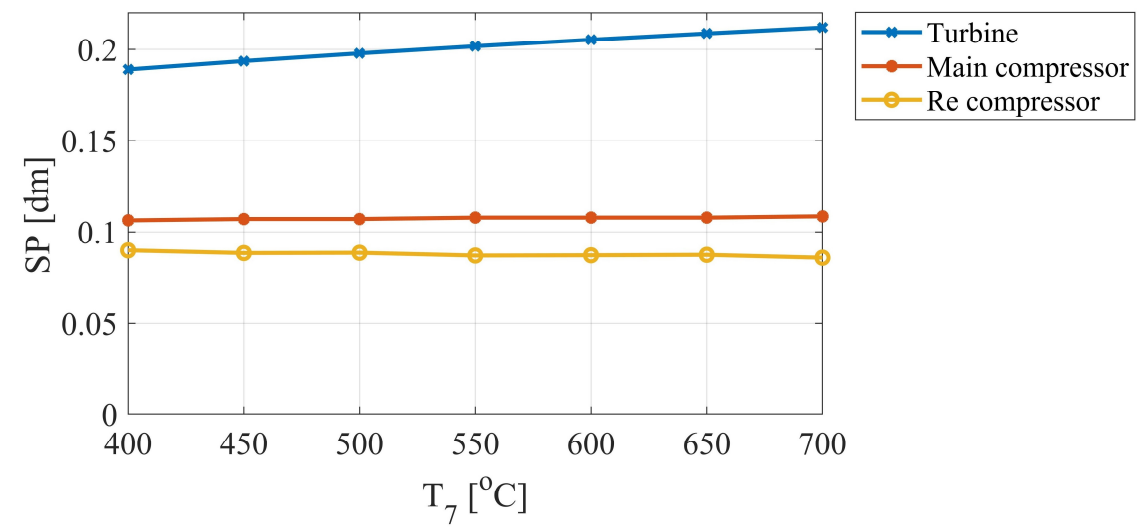

Figure 14. Size parameter $(S P)$ vs. turbine inlet temperature $\left(T_{7}\right)$.

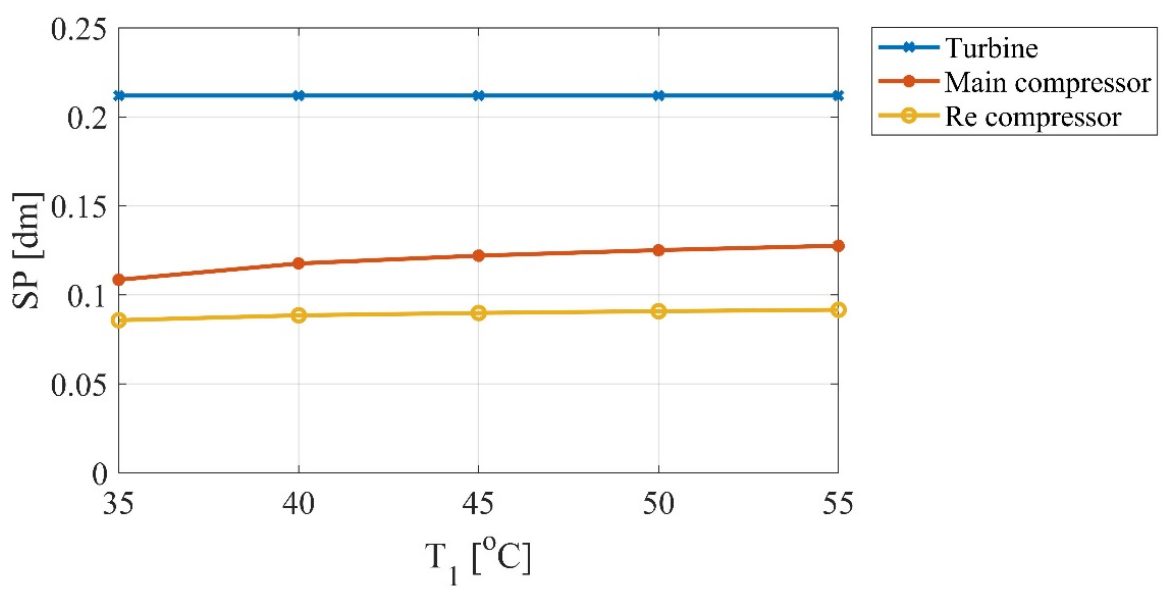

Figure 15. Size parameter $(S P)$ vs. compressor inlet temperature $\left(T_{1}\right)$. 


\section{Conclusions}

The present study investigated seasonal performance analysis of $\mathrm{sCO}_{2}$-based re-compression Brayton power system. From the analysis, the following conclusions were drawn:

- The thermal performance of the considered system is highly sensitive to the turbine's inlet temperate and split mass fraction. For every set of imposed boundary conditions, there exists an optimal value of split mass fraction that tends to minimize the temperature difference between LTR outlet and HTR inlet. It can be concluded that the optimal values of split mass fraction increase with the increase of turbine inlet temperature. Furthermore, the optimal value of the split mass fraction is found as 0.74 , corresponding to the turbine inlet temperature of $700{ }^{\circ} \mathrm{C}$ for which cycle's efficiency $\left(\eta_{\text {th }}\right)$ is $49 \%$.

- The maximum of the cycle's efficiency comes at high total heat transfer area coefficient $\left(U A_{\text {Total }}\right)$ values that in turn increase the cost of the heat exchanger. On the other hand, the cost of the heat exchanger can be reduced by moving the compressor's inlet temperature away from the critical temperature or by lowering the turbine inlet temperature. However, in both scenarios, the cycle's thermal efficiency shall be compromised. Therefore, an optimal trade-off can be established between $U A_{\text {Total }}$ and $\eta_{\text {th }}$ depending on the design objective.

- Exergy destruction is high for high turbine and main inlet temperatures and compressor inlet pressures. The gas cooler is the biggest source of exergy destruction in the cycle. Moreover, exergy destruction for the summer seasons was higher than the winter seasons. The system exergy destruction $\left(I_{\text {Total }}\right)$ has the lowest value of $390 \mathrm{~kW}$ at $35^{\circ} \mathrm{C}$ and $24 \mathrm{MPa}$ in the month of January.

- The size parameter $(S P)$ of the turbine increases with increasing turbine inlet temperature, whereas that of the compressor shows an increase when the main compressor inlet temperature increases. This implies that the total size parameter $\left(S P_{\text {Total }}\right)$ value of the system increases with increasing turbine and compressor inlet temperatures, which the increase the cost of the turbomachinery under these conditions.

\section{Future Work}

- For the $\mathrm{sCO}_{2}$ re-compression Brayton cycle, the thermal efficiency can be further increased if the heat available at the gas cooler is utilized to generate more power. This can be achieved by using the $s \mathrm{CO}_{2}$ cycle in a cascade arrangement with an ORC as a bottoming cycle.

- A tri-generation system can be designed such that the multiple benefits of power, heating and cooling can be obtained from the system. Combined power and heating/cooling systems have the advantage of increasing efficiency by bringing multiple benefits into play.

- The performance of the system can be further improved if the system is optimized using a genetic algorithm such that the investment/maintenance costs of the system are minimized, and at the same time, the efficiency of the system is maximized. For this purpose, multi-objective optimization can be used using variables such as $U A_{\text {Total }}$ and $S P_{\text {Total }}$ to minimize the cost of the heat exchangers and turbomachinery in the system. Furthermore, $\eta_{t h}$ and $\eta_{e x}$ can be used to maximize the efficiency of the system whilst minimizing the exergy destruction due to irreversibilities. The input variables within the most suitable bounded constraints can be defined in the optimization code.

Author Contributions: M.S.S. did the simulation analysis and drafted the manuscript. M.S. did heat exchanger analysis and edited the manuscript. M.-H.K. supervised the research and edited the manuscript. The authors read and approved the manuscript. All authors have read and agreed to the published version of the manuscript.

Funding: This research received no external funding.

Conflicts of Interest: The authors declare no conflict of interest. 


\section{Nomenclature}

Symbols and abbreviations

Cp Specific heat capacity

$e \quad$ Specific exergy of flow $[\mathrm{J} / \mathrm{kg}]$

E $\quad$ Exergy rate [W]

$h \quad$ Specific enthalpy $[\mathrm{J} / \mathrm{kg}]$

I $\quad$ Exergy destruction [W]

IR Irreversibility ratio of the system

$m \quad$ Mass flow rate $[\mathrm{kg} / \mathrm{s}]$

$P \quad$ Pressure [Pa]

$Q \quad$ Heat rate [W]

$S \quad$ Specific entropy [J/kg.K]

$S P \quad$ Turbomachinery size factor

$S P \quad$ Size parameter [m]

$T \quad$ Temperature [K]

UA Heat transfer area coefficient $[\mathrm{W} / \mathrm{K}]$

$W \quad$ Power [W]

$x \quad$ Split mass fraction

Abbreviations

GC

Gas cooler

HTR

High temperature recuperator

HX

Primary heat exchanger

LTR Low temperature recuperator

$\max \quad$ Maximum

$\min \quad$ Minimum

$\mathrm{sCO}_{2} \quad$ Supercritical Carbon dioxide

$\Delta T_{M} \quad$ Log mean temperature difference

Greek symbols

$\eta \quad$ Efficiency

$\varepsilon \quad$ Recuperator effectiveness

$\theta \quad$ Temperature difference

Subscripts

c Cold side

$\mathrm{CO}_{2} \quad$ Carbon dioxide

$h \quad$ Hot side

HTR High temperature recuperator

$H X \quad$ Primary heat exchanger

in Property at inlet

LTR Low temperature recuperator

MC Main compressor

out Property at outlet

ex Exergy

RC Re-compressor

$S \quad$ Isentropic process

th Thermal

T Turbine

$w \quad$ Water

$0 \quad$ Dead state

1,2,3, State points 


\section{References}

1. IPCC. Climate Change 2014: Synthesis Report. Contribution of Working Groups I, II and III to the Fifth Assessment Report of the Intergovernmental Panel on Climate Change; IPCC: Geneva, Switzerland, 2014; ISBN 9789291691432.

2. Mudasar, R.; Aziz, F.; Kim, M.-H. Thermodynamic analysis of organic Rankine cycle used for flue gases from biogas combustion. Energy Convers. Manag. 2017, 153, 627-640. [CrossRef]

3. Yağli, H.; Koç, Y.; Koç, A.; Görgülü, A.; Tandiroğlu, A. Parametric optimization and exergetic analysis comparison of subcritical and supercritical organic Rankine cycle (ORC) for biogas fuelled combined heat and power (CHP) engine exhaust gas waste heat. Energy 2016, 111, 923-932. [CrossRef]

4. Nasir, M.T.; Kim, K.C. Working fluids selection and parametric optimization of an Organic Rankine Cycle coupled Vapor Compression Cycle (ORC-VCC) for air conditioning using low grade heat. Energy Build. 2016, 129, 378-395. [CrossRef]

5. Liu, X.; Wei, M.; Yang, L.; Wang, X. Thermo-economic analysis and optimization selection of ORC system configurations for low temperature binary-cycle geothermal plant. Appl. Therm. Eng. 2017, 125, $153-164$. [CrossRef]

6. Mudasar, R.; Kim, M.-H. Experimental study of power generation utilizing human excreta. Energy Convers. Manag. 2017, 147, 86-99. [CrossRef]

7. Singh, H.; Mishra, R.S. Performance evaluation of the supercritical organic rankine cycle (SORC) integrated with large scale solar parabolic trough collector (SPTC) system: An exergy energy analysis. Environ. Prog. Sustain. Energy 2018, 37, 891-899. [CrossRef]

8. Saeed, M.; Kim, M. Analysis of a recompression supercritical carbon dioxide power cycle with an integrated turbine design/optimization algorithm. Energy 2018, 165, 93-111. [CrossRef]

9. Ahn, Y.; Bae, S.J.; Kim, M.; Cho, S.K.; Baik, S.; Lee, J.I.; Cha, J.E. Review of supercritical $\mathrm{CO}_{2}$ power cycle technology and current status of research and development. Nucl. Eng. Technol. 2015, 47,647-661. [CrossRef]

10. Brun, K.; Friedman, P.; Dennis, R. (Eds.) Fundamentals and Applications of Supercritical Carbon Dioxide $\left(\mathrm{sCO}_{2}\right)$ Based Power Cycles; Woodhead Publishing, Elsevier Science: Cambridge, UK, 2017; ISBN 9780081008058.

11. Crespi, F.; Gavagnin, G.; Sánchez, D.; Martínez, G.S. Supercritical carbon dioxide cycles for power generation: A review. Appl. Energy 2017, 195, 152-183. [CrossRef]

12. Saeed, M.; Khatoon, S.; Kim, M.-H. Design optimization and performance analysis of a supercritical carbon dioxide recompression Brayton cycle based on the detailed models of the cycle components. Energy Convers. Manag. 2019, 196, 242-260. [CrossRef]

13. Aziz, F.; Mudasar, R.; Kim, M.-H. Exergetic and heat load optimization of high temperature organic Rankine cycle. Energy Convers. Manag. 2018, 171, 48-58. [CrossRef]

14. Macchi, E.; Perdichizzi, A. Efficiency prediction for axial-flow turbines operating with non conventional fluids. J. Eng. Power 1981, 103, 718-724. [CrossRef]

15. Aziz, F.; Salim, M.S.; Kim, M.-H. Performance analysis of high temperature cascade organic Rankine cycle coupled with water heating system. Energy 2019, 170, 954-966. [CrossRef]

16. Patel, B.; Desai, N.B.; Kachhwaha, S.S. Optimization of waste heat based organic Rankine cycle powered cascaded vapor compression-absorption refrigeration system. Energy Convers. Manag. 2017, 154, 576-590. [CrossRef]

17. MATLAB-MathWorks-R2017a (Version 9.2). 2017. Available online: https://www.mathworks.com/products/ new_products/release2017a.html (accessed on 12 February 2020).

18. Lemmon, E.; Mc Linden, M.; Huber, M. NIST Reference Fluid Thermodynamic and Transport Properties Database: REFPROP Version 9.1, NIST Standard Reference Database 23. 2013. Available online: http: //www.boulder.nist.gov (accessed on 25 December 2017).

19. Busan Ambient Temperature Data. Available online: https://en.climate-data.org/asia/south-korea/busan/ busan-4114/ (accessed on 15 September 2019).

20. Moran, M.J.; Shapiro, H.N.; Boettner, D.D.; Bailey, M.B. Principles of Engineering Thermodynamics, 7th ed.; John Wiley \& Sons: Hoboken, NJ, USA, 2012.

21. Gao, H.; Liu, C.; He, C.; Xu, X.; Wu, S.; Li, Y. Performance analysis and working fluid selection of a supercritical organic Rankine cycle for low grade waste heat recovery. Energies 2012, 5, 3233-3247. [CrossRef] 
22. Saeed, M.; Kim, M.-H. Thermal and hydraulic performance of $\mathrm{SCO}_{2}$ PCHE with different fin configurations. Appl. Therm. Eng. 2017, 127, 975-985. [CrossRef]

23. Dostal, V.; Driscoll, M.J.; Hejzlar, P. A Supercritical Carbon Dioxide Cycle for Next Generation Nuclear Reactors, MIT-ANP-TR-100, Advanced Nuclear Power Technology Program Report; Massachusetts Institute of Technology: Cambridge, MA, USA, 2004. 